\title{
Freezing Eggs to Get Ahead: A Look at Oocyte Cryo- preservation for Non-Medical Reasons
}

\author{
Jenny Han Zhang ${ }^{1,2}$ \\ ${ }^{1}$ Faculty of Medicine, University of Ottawa \\ ${ }^{2}$ Ottawa Hospital Research Institute
}

\section{ABSTRACT}

The age of first pregnancies for women has been on the rise, partly due to prioritization of career development. Maternal aging is a significant factor affecting fertility, and is correlated with infertility and several adverse pregnancy outcomes. Oocyte cryopreservation (OC), currently recommended to cancer patients pending treatments affecting fertility, is now being explored as an option for extending female fertility due to its efficacy in in vitro fertilization (IVF). However, there is a paucity of data confirming the superiority of the procedure over natural pregnancy in healthy women, given the potential complications. Caution in recommending the procedure should therefore be taken.

\section{RÉSUMÉ}

L'âge des premières grossesses chez les femmes a augmenté, en partie à cause de la hiérarchisation du développement de carrière. Le vieillissement maternel est un facteur important affectant la fertilité, et est corrélé avec l'infertilité et plusieurs résultats défavorables de la grossesse. La cryoconservation des ovocytes (CO), recommandée aux patients cancéreux en attendant les traitements affectant la fertilité, est actuellement explorée comme une option pour augmenter la fertilité féminine en raison de son efficacité dans la fécondation in vitro (FIV). Cependant, il y a un manque de données confirmant la supériorité de la procédure sur la grossesse naturelle chez les femmes en bonne santé, étant donné les complications potentielles. La prudence dans la recommandation de la procédure devrait donc être prise.

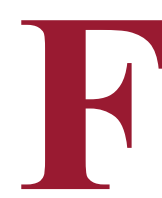
irst comes love, then comes marriage, then comes baby in the baby carriage. For a long time, this has been upheld as the dream that little girls are supposed to have. With the feminist movement slowly gaining rights for women in recent decades, gender equality is starting to take hold in many aspects of society. One such aspect is the workforce, where women now stand proudly as CEOs, scientists, teachers, doctors; in fact, they play a vital role in all fields of work in Canada. The age at which women have their first pregnancies has also been on the rise, with $42.8 \%$ of first-time mothers being over 30 years of age in 2013, up from $26.6 \%$ in 1993 [1]. The peak of female fertility is during a woman's early to mid-twenties, but that is also a critical period for career establishment [2,3]. Pregnancy becomes gradually more difficult as maternal age increases, and several risk factors for both the mother-to-be and the baby begin to arise [3]. Many careers can force a choice to be made between work and family, yet for many, the traditional dream of the baby carriage and the newer dream of career success are not mutually exclusive ideals. Despite these challenges, women have the right to both a fulfilling career and a family.
"Taking control of fertility" is a phrase often heard in reference to the accessibility of effective contraception. Given our resources in Canada, women can more easily avoid pregnancy. Unfortunately, the converse is not true. Technology to extend female fertility such as oocyte cryopreservation (OC), or the preservation of eggs through freezing, sounds like something out of a sci-fi novel, and yet it is a procedure that is rising in popularity. In the science community, it is being debated whether or not to use OC for non-medical purposes. Meanwhile, society has taken interest in the possibilities with optimistic excitement.

\section{AGE AS A RISK FACTOR IN FEMALE FERTILITY}

Women are still having children in their 30 s and even 40s. Thus, on the surface, the age effect on fertility does not seem like a significant issue. However, this glosses over the experiences and challenges that stand in the way of having children at a later age. Not only does the average length of time it takes for a woman to conceive increase with age, but even upon conception miscarriage is a concern. The likelihood of fetal loss is strongly correlated with maternal age, increasing from less than $10 \%$ in women in their early 20 s to nearly $75 \%$ in mothers age 45 and over, and this is observed with natural pregnancy

Keywords: Reproduction; Women's Health; Fertility; Oocyte Cryopreservation; Oocyte Vitrification; Infertility; IVF 
or through IVF using the patient's own oocytes $[4,5]$. This may partly be due to the increased incidence of trisomic conception such as Down syndrome, a result of improperly executed meiosis during oocyte development [6]. For women in their 20s, the occurrence of trisomic conception is only around $2 \%$, a shocking contrast to the $35 \%$ prevalence for women in their 40s [7].

Pregnancy is possible later in life, but it becomes more difficult with age. Furthermore, adverse pregnancy outcomes that become increasingly prevalent with maternal aging, such as gestational diabetes and preterm delivery, can add excessive emotional and financial burden to what should be a joyous period of one's life [5].

\section{COUNTERING THE MATERNAL AGE PROBLEM}

In Vitro Fertilization (IVF)

Infertility is not an insignificant problem for men or women. As such, in vitro fertilization (IVF) is gaining popularity. The procedure is even partially covered by the Ontario and Quebec provincial governments, and the federal government also supports its use with a $15 \%$ tax break for associated costs [8,9]. However, at the moment it does not guarantee success; only around half of the couples that begin treatment succeed in giving birth to a child [10]. The factors affecting fertility are still largely a mystery, and there are ongoing studies to refine the procedure, or attempt to predict the IVF outcome based on factors such as cause and duration of infertility, ethnicity, and so on [10]. One clear conclusion from these studies is that maternal age and therefore oocyte age is a major factor affecting the success of IVF treatment.

One solution to counter this problem is the use of donor eggs from young, healthy women in their 20s. While this increases the success rates, some women are understandably hesitant about choosing this option, as they will not be able to contribute genetically to their children. To address this, the technique for oocyte vitrification, a form of oocyte cryopreservation, has been refined in recent years and in 2013 was officially declared as no longer experimental by both the Society for Assisted Reproductive Technology (SART) and the American Society for Reproductive Medicine (ASRM) [11].

For those who prioritize having a genetic link with their offspring, oocyte cryopreservation has the potential to become a useful tool in fertility treatment as it demonstrates similar results to IVF involving fresh oocytes [12]. This sounds very op- timistic for expanding reproductive freedom for women, but reality may paint a slightly different picture.

\section{Preservation of Fertility}

Oocyte cryopreservation (OC) can be defined as the preservation of oocytes through freezing. Vitrification is a type of cryopreservation, using ultra-fast freezing rather than the traditional slow freezing process that results in the formation of ice crystals, yielding deleterious results [13]. Research to refine techniques for both oocyte cryopreservation, as well as IVF, is ongoing in order to improve live-birth occurrences.

Presently, it is recommended that cancer patients of childbearing age whom are due to undergo treatments that may result in gonadotoxicity be engaged in a discussion regarding a potential loss of fertility. Counselling for these life changing events are accepted as the standard of care, and oocyte vitrification is sometimes offered as an option to preserve fertility for the future $[14,15]$. For women who face an immediate loss of fertility, the choice to undertake this procedure is understandable. However, there is now rising interest in using $O C$ as a way to delay childbirth in healthy women [16].

\section{Elective Oocyte Cryopreservation}

Full control over fertility is a tempting idea, and the benefits of having that choice are abundantly clear. Being able to push back the pressures of childbirth and parenthood without worrying that by delaying, you are increasing the chances of congenital disorders would certainly be beneficial to many women. However, our knowledge and standard procedures cannot support such confidence at present, as there are several risk factors to consider, as well as a body of literature that is far from robust to support the benefits of $\mathrm{OC}$ for non-medical reasons.

The first step of $\mathrm{OC}$ is oocyte retrieval, a process that may largely be a mystery to the general population, and involves certain health risks. Firstly, obtaining the oocytes for freezing requires the patient to undergo hormonal treatment for ovarian stimulation. This treatment can be lengthy, and can cause side effects such as hot flashes, nausea, and dizziness depending on the type of medicine being used [17]. One potential adverse outcome, ovarian hyperstimulation syndrome (OHSS), can result from the use of human chorionic gonadotrophin (hCG), the hormone used to promote ovulation. This hormone is administered 36 hours prior to the procedure and in rare cases, OHSS can result in patients who are overly responsive to hormonal 
stimulation. OHSS manifests as cystic enlargement of ovaries, and the symptoms can include severe abdominal pain, nausea, and hypercoagulation. Severe cases can even result in fatality. For women suffering from polycystic ovary syndrome, this is particularly dangerous [18]. Medical professionals, however, have strategies put in place regarding hCG dosage and hormone regime for patients in order to prevent this from happening [19].

Other risks involve the surgery portion of the retrieval process. Oocyte retrieval requires sedation, and as with all surgical procedures, there are risks involved in both the surgery and the use of anaesthesia. However, it is a short and relatively safe procedure lasting only a half hour, and the patient is able to leave shortly after. Currently the process used is transvaginal oocyte retrieval (TVOR), during which a catheter tipped with a needle is guided via ultrasound through the vaginal wall to enter follicles. To obtain the oocytes, mild suction pressure is used [20]. Complications of TVOR include haemorrhage and pelvic abscesses, although they only occur in around $0.08 \%$ and $0.6 \%$ of cases, respectively [21].

Given the risks, assurance that the procedure will successfully result in live birth down the road would be ideal. However, there is a paucity of data available that addresses fertility preservation in healthy women. While it is promising that cryopreserved oocytes have IVF success rates on par with fresh oocytes, most studies focus on women with low fertility. Elective $\mathrm{OC}$, on the other hand, would typically be considered by young women with no fertility concerns. Unfortunately, there are no current studies comparing $O C$ to naturally occurring pregnancy later in life for this demographic. Despite this, many recently surveyed women are in support of using oocyte cryopreservation as a means for extending fertility, but this openness towards the procedure has yet to translate into data [19]. A recent survey of 96 healthy Australian women who had opted for OC indicated that only 6 returned for the oocytes; of those, only half succeeded in giving birth [16]. The mean age for this cohort, however, was 37 years for oocyte freezing, which is past the point of peak fertility, and the small sample size makes this study only minimally effective at demonstrating the potential of OC for young, healthy women hoping to extend their fertility. Despite this, the study is one of the few that assess the efficacy of non-medical OC [16].

Here we have a conundrum. Without data that explicitly proves the procedure's efficacy at preserving fertility, how can we recommend the procedure? And if we do not recommend this procedure, how can data be obtained? Surveys of a cohort of European women between the ages of 30-39 shows that many are optimistic towards elective $\mathrm{OC}$, and while there is controversy surrounding the topic, fertility clinics worldwide are offering fertility preservation services [11]. However, current information surrounding the procedure are not made widely known. A 2017 study evaluating 376 SART fertility clinics found that of the $90 \%$ offering elective OC, less than a fifth disclose the cost [22]. More concerning is the lack of a disclaimer that this procedure cannot guarantee future fertility in $90 \%$ of these clinics [22]. Information is vital in making a decision regarding any surgical procedures, and yet it seems that the facilities providing the services are not fully transparent with the potential outcomes of OC. The lack of information may potentially mislead women into considering the option of elective $\mathrm{OC}$ and overestimating the security that this procedure could provide.

\section{CONCLUSION}

Both the science community and society at large are becoming more interested in the idea of elective oocyte cryopreservation, which has the potential to extend the fertile years of women who may feel conflicted between pursuing a career and having a child. However, while many fertility clinics are pushing for the procedure in young healthy women in prime reproductive years, there is little data to support any advantages of OC over natural conception slightly later in life. Furthermore, several health risks involved in oocyte retrieval can cause complications that would not otherwise arise.

More data is needed before oocyte cryopreservation can be recommended with any kind of certainty, and this can only be obtained through more reproductively healthy women opting for OC. As to whether the procedure should be recommended, there is no clear answer. However, it is vital to provide all the necessary information to women considering this option so that they can make a well-informed decision with tempered expectations. The future is exciting as techniques in preserving fertility continue to improve, and the reproductive science community is constantly gaining a deeper understanding into the mechanisms surrounding fertility and gamete health. Certainly, it is within the realm of possibility that women can someday truly take full control of their fertility. 


\section{REFERENCES}

1. Statistics Canada - Government of Canada. Trends in Canadian births, 1993 to 2013 [Internet]. Statistics Canada. 2016 Oct 26 [cited 2017 Sept 27] . Available from: http://www.statcan.gc.ca/pub/82-625-x/2016001/ article/14673-eng.htm\#a2.

2. Liu K, Case A. Advanced reproductive age and fertility. J Obstet Gynaecol Canada. 2011;33(11):1165-75.

3. Schwartz D, Mayaux MJ. Female fecundity as a function of age: results of artificial insemination in 2193 nulliparous women with azoospermic husbands. Federation CECOS. N Engl J Med. 1982;306(7):404-6.

4. Spandorfer S, Davis O, Barmat L, Pak C, Rosenwaks Z. Relationship between maternal age and aneuploidy in in vitro fertilization pregnancy loss. Fertil Steril. 2003;81(5):1265-9.

5. Cleary-Goldman J, Malone F, Vidaver J, et al. Impact of maternal age on obstetric outcome. Obstet Gynecol. 2005;105(5):983-90.

6. Hassold T, Hunt P. Maternal age and chromosomally abnormal pregnancies: what we know and what we wish we knew. Curr Opin Pediatr. 2009;21(6):703-8.

7. Duncan FE. Egg quality during the pubertal transition-is youth all it's cracked up to be? Front Endocrinol (Lausanne). 2017;8:1-5.

8. Government of Ontario. Get fertility treatments [Internet]. Government of Ontario. 2017 May 9 [cited 2017 Sept 27]. Available from: https://www.ontario.ca/page/get-fertility-treatments.

9. The Montreal Fertility Centre. Quebec Program of Assisted Reproduction [Internet]. The Montreal Fertility Centre. 2017 [cited 2017 Sept 27]. Available from: http://www.montrealfertility.com/quebec-program-of-assistedreproduction/.

10. Dhillon RK, McLernon DJ, Smith PP, et al. Predicting the chance of live birth for women undergoing IVF: a novel pretreatment counselling tool. Hum Reprod. 2016;31(1):84-92.

11. Chian R-C, Xu Y, Keilty D. Cryopreservation of mammalian gametes and embryos. New York, NY: Humana Press; 2017. Chapter 3, Current challenges in immature oocyte cryopreservation; p. 33-44.

12. Cobo A, Kuwayama M, Pérez S, Ruiz A, Pellicer A, Remohí J. Comparison of concomitant outcome achieved with fresh and cryopreserved donor oocytes vitrified by the Cryotop method. Fertil Steril. 2007;89(6):1657-64.

13. Danasouri IE, Selman H. Vitrification versus conventional cryopreservation technique. Middle East Fertil Soc J. 2005;10(3):205-6.

14. Massarotti C, Scaruffi P, Lambertini M, Remorgida V, Del Mastro L, Anserini P. State of the art on oocyte cryopreservation in female cancer patients: A critical review of the literature. Cancer Treat Rev. 2017;57:50-7.

15. Noyes N, Labella PA, Grifo J, Knopman JM. Oocyte cryopreservation: a feasible fertility preservation option for reproductive age cancer survivors. J Assist Reprod Genet. 2010;27(8):495-9.

16. Hammarberg K, Kirkman M, Pritchard N, et al. Reproductive experiences of women who cryopreserved oocytes for non-medical reasons. Hum Reprod. 2017;32(3):575-81.

17. Flinders Fertility. Information statement - ovulation induction risks [Internet]. Flinders Fertility. 2016 [cited 2017 Sep 30]. Available from: http://www. flindersfertility.com.au/Research-Resources/Information-Statements/Ovulation-Induction-Risks.

18. Kumar P, Sait SF, Sharma A, Kumar M. Ovarian hyperstimulation syndrome. J Hum Reprod Sci. 2011;4(2):70-5.

19. Onalen G, Zeyneloglu HB. Manual of ovulation induction and ovarian stimulation protocols. In: Allahbadia G, Merchant R, eds. Ovarian Stimulation Procedures. 3rd ed. JP Medical Ltd.; 2016. 649 p.

20. Rose BI. Approaches to oocyte retrieval for advanced reproductive technology cycles planning to utilize in vitro maturation: a review of the many choices to be made. J Assist Reprod Genet. 2014;31(11):1409-19.

21. Choudhary RA, Bhise NM, Mehendale A V, Ganla KN. Ureteric injury during transvaginal oocyte retrieval (TVOR) and review of literature. J Hum Reprod Sci. 2017;10(1):61-4.

22. Zore T, Joshi N, Schon SB, Masson P, Chan JL. Assessment of fertility clinic websites on oocyte cryopreservation (OC). Fertil Steril. 2017;108(3):e189. 